Hay que reseñar que, si bien es excepcional (0,3\%-0-8\%), se recoge en la literatura la posibilidad de regresión espontánea del tumor en toda su extensión aún sin nefrectomía previa $(5,7)$.

En cuanto al pronóstico de este tipo de metástasis hay que resaltar que, es mejor en el caso de una lesión solitaria, $y$, dentro de ellas, tienen mejor evolución las que aparecen asincrónicamente en la evolución del proceso que aquellas de aparición sincrónica con el tumor primario. 0 tro determinante pronóstico importante es el tiempo transcurrido entre el diagnóstico del tumor (en las asincrónicas) y la aparición del implante metastásico. La supervivencia general de las metástasis cutáneas es de $50 \%$ a 1 año, 20\% a 3 años, prácticamente nula a 5 años. En 1993 Couillard y de Vere $W$ hite evidenciaron una supervivencia a 5 años del $13 \%$ al $50 \%$ para las metástasis cutáneas solitarias tras la resección y de un $0 \%$ a $8 \%$ para los casos de metástasis múltiples. $(1,2,7)$.

BIBUOGRAFIA y LECTURAS

RECOMENDADAS (*lectura de interés y

**lectura fundamental)

*1. DORIRAJAN, L.N.; HEMAL, A.K.; ARON, M.: "Cutaneous metastases in renal cell carcinoma". Urol. Int., 63: 164, 1999.

2. CHANDLER, J.; HEANEY, W.J.A.: "Metastatic renal cell carcinoma presenting as a skin nodule : case report and review of the literature". J. Urol., 152: 2094, 1994.

*3. KOROUPAKIS, D.; PATSEA, E.; SOFRAS, F. y cols.: "Renal cell carcinoma metastases to the skin : a not so rare case?". B.J.U., 75: 583, 1995.

4. SHIGHEIKO, K.; SATOSHI, T.; MASAHARU, N.: "Renal cell carcinoma metastatic to the skin". Anticancer Researh, 20: 1939, 2000.

5. CUCKOW, P.; DOYLE, P.: "Renal cell carcinoma presenting in the skin". J. of the Royal Society of Medicine, 84: 497,1991.

6. SNOW, S.; MADJAR, D.; REIZNER, G.: "Renal cell carcinoma metastatic to the scalp .Case report and review of the literature". Dermatol. Surg., 27: 192, 2001.

7. WALSH, R.; VAUGHAN, R.: "Campbell's Urology". Eight edition. 2002.

8. WEISS, L.; HARLOS, J.P.; TORHORST ,J.: "Metastatic patterns of renal cell carcinoma: an analysis of 687 necropsies". Cancer Res. Clin. Oncol., 114: 605, 1988.

9. HELlSTEN, S.; BERGE, T.; LINEL, F.: "Clinically unrecognized renal carcinoma: aspects of tumor morphology, lymphatic and haematogenous metastasic spread". Br. J. Urol., 55: 166, 1983.
Casos C línicos

Arch. Esp. Urol., 58, 3 (250-253), 2005

\section{REGRESIÓN ESPONTÁNEA DE TROMBOSIS VENOSA EN UN CASO DE CARCINOMA RENAL}

Antonio Jalón Monzón, Francisco Javier Regadera Sejas, Jorge García Rodríguez, Francisco Javier M artínez G ómez, Alberto Sánchez Trilla, Jesús M aría Fernández Gómez, Juan Javier Rodríguez M artínez, O scar Rodríguez Faba, Roberto Carlos González Álvarez, M iguel Álvarez Múgica.

Hospital Universitario Central de Asturias. 0 viedo. Asturias. España.

Resumen.- O BJETIVO: Describir el primer caso de regresión espontánea de trombosis de vena renal y cava inferior en un paciente con carcinoma de células renales. MÉTO DO / RESULTADO : Se describe el caso de una mujer diagnosticada de masa renal con trombosis de venas renal y cava. En los estudios de extensión previos a la nefrectomía radical se constata la regresión de dicho trombo que se confirma posteriormente tras la nefrectomía.

CONCLUSIÓN: La regresión espontánea de metástasis de carcinoma de células renales se estima menor al $1 \%$. Este es el primer caso descrito en la literatura que afecta a una trombosis tumoral de venas renal y cava inferior.

Palabras clave: Regresión espontánea. Carcinoma renal. Trombosis venosa.

Antonio Jalón Monzón

Servicio de Urología

Hospital Universitario C entral de Asturias

C elestino Villamil, $s / n$

330060 viedo. Asturias. (España)

Trabajo recibido: 30 de agosto 2004 
Summary.- O BJEC TIVES: To report the first case of spontaneous regression of renal vein and inferior vena cava thrombus in a patient with renal clear cell carcinoma. METHODS/ RESULTS: We describe the case of a woman with the diagnosis of renal mass with venous thrombus of the renal vein and inferior vena cava. Extension studies before radical nephrectomy showed regression of the thrombus which was confirmed during nephrectomy.

CONCLUSIONS: Spontaneous regression of clear cell renal carcinoma metastases is estimated below $1 \%$ of the cases. This is the first case report of regression of a tumoral thrombus of the renal vein and inferior vena cava.

Keywords: Spontaneous regression. Renal carcinoma. Vein thrombosis.

\section{INTRODUCCIÓN}

Los tumores del parénquima renal representan aproximadamente el $3 \%$ de los tumores renales del adulto. Más del $80 \%$ de los cánceres renales asientan en el parénquima mientras que el resto se localizan en la pelvis renal. Prácticamente la totalidad de los tumores del parénquima son adenocarcinomas mientras que los tumores que asientan en la pelvis son, en su mayoría, carcinomas de células transicionales.

Sólo el $40 \%$ de los pacientes tienen enfermedad confinada al riñón en el momento del diagnóstico y desafortunadamente, un 25 a $30 \%$ de pacientes se presentan con metástasis a distancia $(1,2)$. Si el tumor no puede ser completamente resecado el curso es generalmente pro-

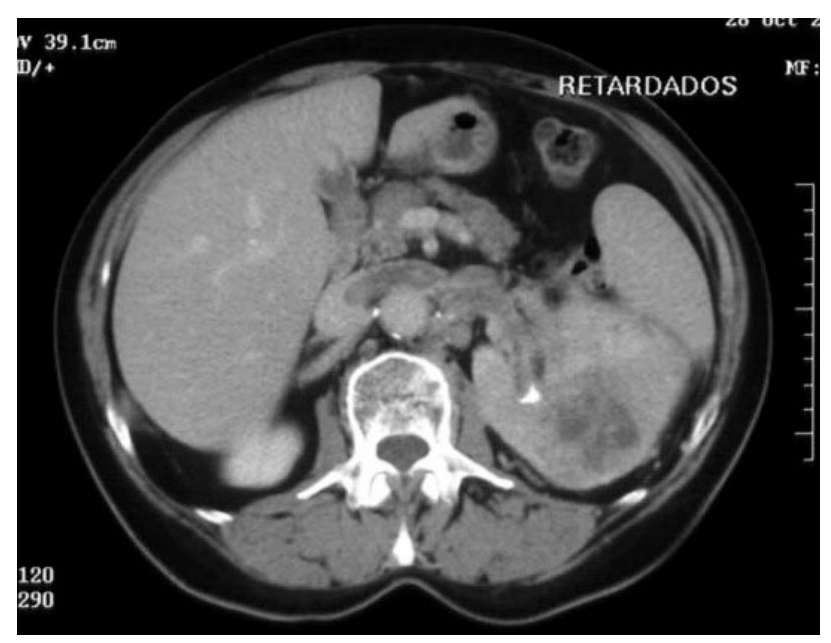

FIG URA 1. Tomografía Computarizada: gran masa renal izquierda con trombosis de venal renal y vena cava inferior. gresivo, con una media de supervivencia de 12 a 18 meses después de las metástasis. El $85 \%$ de recidivas ocurren en los primeros tres años.

Una de las característica del carcinoma de células renales (CCR) es su marcada tendencia a crecer intraluminalmente en el sistema venoso, especialmente en vena renal y vena cava inferior, con una frecuencia estimada del 21 $35 \%$ y $4-10 \%$ de los casos respectivamente $(3,4)$.

La regresión espontánea de las metástasis han sido descritas práctica mente en todos los tumores aunque los cuatro tipos más frecuentes son el hipernefroma, neuroblastoma, melanoma y el coriocarcinoma (5).

Las metástasis afectan más comúnmente a pulmón, hígado, huesos largos y cerebro, siendo las de localización pulmonar las que regresan con más frecuencia $(2,5)$.

Presentamos el primer caso descrito en la literatura, que así nos consta, de regresión espontánea de una trombosis tumoral que afectaba a vena renal, vena cava inferior y vena ovárica izquierda.

\section{CASO CĹNICO}

Mujer de 73 años, sin antecedentes personales de interés, que en ecografía realizada por dolor tipo cólico a nivel de fosa renal izquierda se le descubrió una masa renal izquierda. La TC realizada a posteriori (Figura 1) se informó como de gran masa renal izquierda compatible con hipernefroma con trombosis de vena renal izquierda y parcial de vena cava inferior, extendiéndose también a vena ovárica izquierda.

Se realizó RM (Figura 2) con la finalidad de buscar más

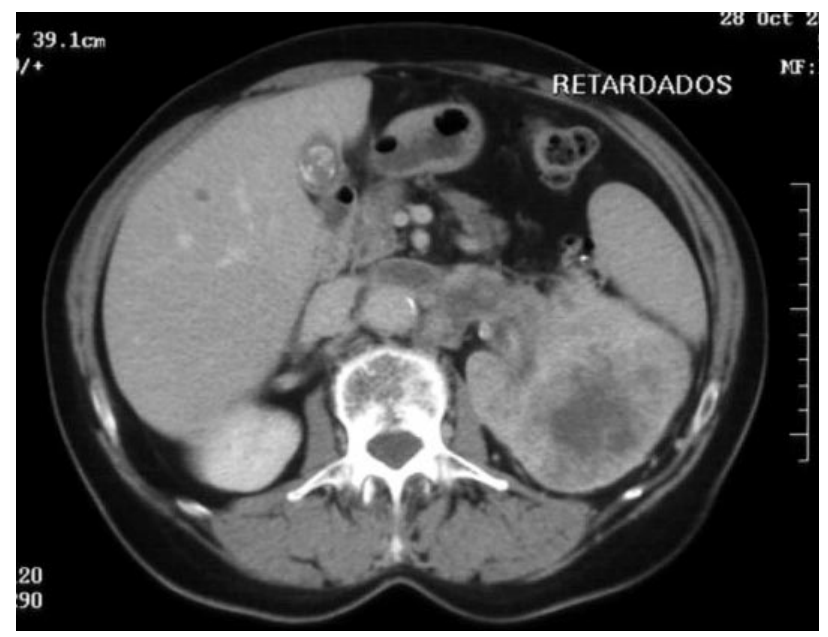

FIG URA 2. Resonancia Magnética: masa renal izquierda con trombosis de vena renal y pequeño trombo mural en su desembocadura. 
información acerca de la invasión neoplásica en vena cava inferior, confirmándose la existencia de voluminosa tumoración de $7 \times 5 \times 6 \mathrm{~cm}$ en riñón izquierdo con trombosis de vena renal izquierda y pequeño trombo mural en su desembocadura en cava pero sin advertirse trombo en la luz de la cava intrahepática así como tampoco adenopatías regionales en rango patológico.

La paciente en ningún momento durante el tiempo transcurrido entre estos dos estudios de imagen refirió diseña, hemoptisis ni otra clínica que sugiriese el desprendimiento del trombo en vena cava. Así mismo, tampoco inició tratamiento alguno que pudiese disolver el trombo.

Se decidió realizar nuevo TC abdominal (Figura 3) para confirmar los hallazgos de la RM informándose este como de masa renal izquierda de gran tamaño compatible con hipernefroma sin presencia de trombosis de vena renal 0 cava, presentes en estudios anteriores.

En la gammagrafía ósea con Tc99m-M DP no se observaron acúmulos óseos patológicos.

Se realizó nefrectomía radical izquierda evidenciando como hallazgo intraoperatorio un dudoso trombo de vena renal distal por lo que se liberó la vena hasta su cruce con la aorta comprobándose su permeabilidad total a ese nivel.

El diagnóstico de la pieza de nefrectomía fue de carcinoma de células claras (grado III de Fuhrman), con bordes de resección a nivel de uréter, arteria y vena renal libres de tumor.

\section{DISCUSIÓN}

EI CCR es predominantemente un tumor de adultos siendo más prevalente en la sexta década en hombres y en la séptima década en mujeres. La regresión espontánea parece

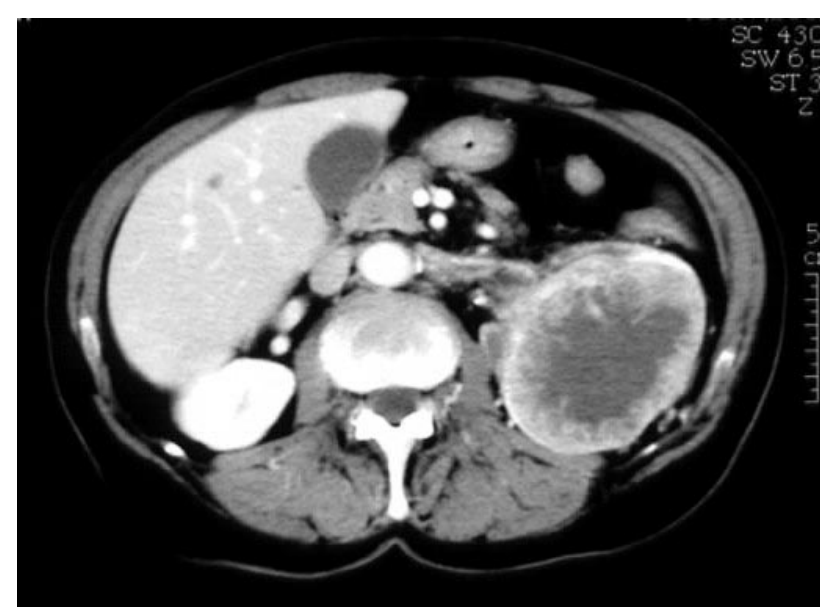

FIG URA 3. Tomografía Computarizada: masa renal izquierda sin presencia de trombosis venosa. predominar en grupos de menor edad. Los cuatro tipos de tumores que con más frecuencia presentan RE son el hipernefroma, neuroblastoma, melanoma y el coriocarcinoma. A unque estas cuatro entidades representan menos del $4 \%$ de todos los cánceres, ellos constituyen más del $50 \%$ de todos los casos de regresión espontánea (5).

La regresión espontánea (RE) es definida por Everson y Cole (6) como la "desaparición parcial o completa del tumor maligno en ausencia de todo tratamiento 0 en presencia de tratamiento considerado como no adecuado". La RE no es sinónimo de curación y por ello los mismos autores definen 6 categorías distintas: 1) regresión del tumor primario; 2 ) regresión de metástasis con confirmación histológica; 3) regresión de metástasis sin confirmación histológica; 4) regresión de supuestas metástasis diagnosticadas radiológicamente; 5 ) estabiliza ción tumoral y 6) recurrencia tardía.

La frecuencia de este fenómeno se estima menor del 1\% $(7,8)$, no habiéndose descrito la RE del tumor primario siendo excepcional la de las metástasis esqueléticas, cerebrales e intestinales. El pulmón es el órgano donde mayor número de regresiones se han descrito $(9,10)$. La mayor capacidad del pulmón para lograr regresiones, comparándola con la de otros órganos, se cree que se debe a su constante exposición a antígenos externos y su riqueza en macrófagos, linfocitos e Inmunoglobulina A. La regresión puede ser parcial o completa, de duración variable, tras o sin nefrectomía, y no implica curación de la enfermedad neoplásica. Recientemente ha sido descrita la regresión de una metástasis coroidea tras nefrectomía (11).

Fueron descritas la regresión espontánea de trombos en vena renal y cava inferior pero en paciente sin cáncer renal, mieloma múltiple, síndrome nefrótico ni alteraciones en la coagulación (12). De este modo describimos el primer caso de mujer con cáncer renal y trombosis de vena renal y cava con regresión espontánea de estas últimas.

El descubrimiento de una masa renal con trombo en cava es generalmente indicativo de CCR, siendo ocasionalmente visto en carcinoma de células transicionales 0 en pacientes con historia de tumor maligno primario extrarrenal asociado con metástasis en riñón con trombo en vena renal y cava $(13,14)$.

Varios han sido los mecanismos propuestos para explicar esta regresión espontánea: causas hormonales, fiebre, infecciones y otras condiciones como factores de crecimiento o citoquinas, eliminación del carcinógeno, necrosis tumoral 0 inhibición de la angiogénesis, factores psicológicos 0 apoptosis (15). La explicación más aceptada 
parece ser la mediación del sistema inmune (5) cuya modificación pueda estar relacionada con cambios hormonales, trauma quirúrgico, infección o fiebre.

\section{BIBUOGRAFIA y LECTURAS RECOMENDADAS (*lectura de interés y **lectura fundamental)}

*1. GOLIMBU, M.; JOSHI, P.; SPERBER, A.: "Renal cell carcinoma survival and prognostic factors". Urology, 27: 291, 1986.

*2. YOUNG, R.C.: "Metastatic renal-cell carcinoma: what causes occasional dramatic regressions?". The New England Journal of Medicine, 338: 1305, 1998.

3. LJUNGBERG, B.; STENLING, R.; OSTERDAHL, B. y cols.: "Vein invasion in renal cell carcinoma. Impact on metastatic behaviour and survival". J. Urol., 154: $1681,1995$.

4. SOSA, R.E.; MUECKE, E.L.; DARRACOTT, G. y cols.: "Renal cell carcinoma extending into the inferior vena cava. The prognostic significance of the level of vena caval involvement”. J. Urol., 132: 1097, 1984.

*5. KALLMEYER, J.C.; DILTRICH, O.C.: "Spontaneus regression of metastases in a case of bilateral renal cell carcinoma". J. Urol., 148: 138, 1992.

*6. EVERSON, T.C.; COLE, W.H.: "Spontaneous regression of cancer". Philadelphia: W.B. Saunders Co., 1187, 1966.

7. NATHAN, P.; GORE, M.: "The immunotherapy of renal cell carcinoma". Immunnology for surgeos. $\mathrm{Ch}$. 14; 295-307. Springer-Verlag. London 2002.

8. SNOW, R.M.; SCHELLHAMMER, P.F.: "Spontaneous regression of renal cell carcinoma". Urology, 20: 177, 1982.

9. RAUH, S.; ONHEM, C.; RIES, F. y cols.: "Spontaneous regression of pulmonary metastases in renal cancer". Bull Soc. Sci. Med. Grand. Duche Luxemb., 135: 39, 1998.

10. VOGELZANG, N.J.; PRIEST, ER.; BORDEN, L.: "Spontaneous regression of histologically proved pulmonary metastases from renal". J. Urol., 148: 1247, 1992.

11. HAMMAD, A.M.; PARIS, G.R.; VAN HEUVEN, W.A. y cols.: "Spontaneous regression of choroidal metastasis from renal cell carcinoma". Am. J. Ophthalmol. Jun.; 135: 911, 2003.

*12. CHIKARAISHI, T.; KOBAYASHI, S.; HARADA, H. y cols.: "Idiopatic and spontaneously regressing thrombus in right renal vein and inferior vena cava". Int. J. Urol., 4: 83, 1997.

13. FRASER, E.T.; COAKLEY, F.V.; MENG, M.V. y cols.: "Computed tomography and magnetic resonance imaging of inferior vena caval thrombus associated with metastasis to the kidney". J. Comput. Assist. Tomogr., 28: January/February 2004.

14. MIYAZATO, M.; YONOU, H.; SUGAYA, K. y cols.: "Transitional cell carcinoma of the renal pelvis forming tumor thrombus in the vena cava". Int. J. Urol., 8: 575, 2001.

**15. PAPAC, J.: "Spontaneous regression of cancer: possible mechanisms". In Vivo, 12: 571, 1998.
Casos C línicos

Arch. Esp. Urol., 58, 3 (253-255), 2005

\section{AMILOIDOSIS VESICAL PRIMARIA LOCAL- ZADA IDIOPÁTICA.}

\author{
Carlos Pascual Mateo, María Antonia $N$ ieto \\ $G$ allego ${ }^{1}, N$ uria Rodríguez $G$ arcía, M arcos Luján \\ $G$ alán y Antonio Berenguer Sánchez.
}

Servicios de Urología y Anatomía Patológica ${ }^{1}$. Hospital Universitario de G etafe. Madrid. España.

Resumen.- O BJETIVO : Describir un caso de amiloidosis vesical localizada idiopática.

MÉTO DOS: Se estudió un paciente varón con hematuria a sinto mática mediante resección transuretral.

RESULTADO S: El resultado histológico de las muestras enviadas informó de amiloidosis vesical. El estudio posterior no demostró depósitos de material amiloide en otra localización ni etiología demostrable de la amiloidosis. CON C LUSIO N ES: La amiloidosis vesical localizada idiopática es una entidad poco frecuente cuya principal forma de presentación es la hematuria y que puede ser difícil de diferenciar de una patología neoplásica de urotelio vesical.

Palabras clave: Amiloidosis. Vejiga. Hematuria.

Antonio Berenguer Sánchez.

Servicio de Urología.

Hospital Universitario de $\mathrm{G}$ etafe.

C tra de Toledo, Km. 12.500

$G$ etafe. Madrid. (España)

e-mail: uroget@terra.es

Trabajo recibido: 29 de septiembre 2004 